\title{
A View of the Adoption of Green Building Concept in Construction Projects in Federal University of Technology Owerri
}

\author{
Nkeleme Emmanuel Ifeanyichukwu, OkoyeUjunnwa Callista
}

\begin{abstract}
The construction industry is undergoing a green revolution where the idea of sustainable construction is fast gaining popularity. Green buildings are regarded as economical, resource efficient and environmentally friendly buildings compared with the convectional buildings. Therefore,considering the necessity of this new concept, it is expedient to view the reality of the adoption of green building concept in construction projects in Federal University of Technology Owerri. The research implored the combination of a quantitative and qualitative approach. The focus was on the buildings within FUTO with more concentration of new buildings constructed between 2012 and 2017. The primary data was obtained through observations and by administering questionnaires to individuals who are lecturers, familiar with the design, construction and management of the buildings. For quantitative method, parameters that define green construction with a range of variables from minimal to complete incorporation of the elements, determined the degree of conformity. The degree of adoption was statistically analyzed on the sampled buildings. The result from the research revealed among others that the condition that calls for Green Building elsewhere especially in the developed nation does exist in Nigeria, particularly in the construction project in FUTO, considering the fact that there is a substantial environmental damage from construction work and deviations from other green criteria. The research therefore call on relevant stakeholder to consider the concept of green building as a core criteria for any construction plan.
\end{abstract}

Index Terms- Green Building;Sustainability; Construction;Cost efficiency; Environment friendly.

\section{INTRODUCTION}

The term "green" and "sustainable" constructions are often used interchangeably, though there are shades of meaning implied by each. Sustainable construction has evolved as a guiding paradigm to create a new kind of built environment: "one that meets the needs of humans in the present without limiting the ability of future generations to meet their own needs" (Ofori, 2001). The creation, operation and disposal of the built environment dominate humanity's impact on the natural world (Kibertet al., 2000). For Nigeria, construction is undoubtedly a key sector of the economy, not so much because of its 3\% GDP contribution, but because of its contribution towards reducing high unemployment and its multiplier effect on other economic activities (NBS, 2014).

Nkeleme Emmanuel Ifeanyichukwu, Department of Building, Federal University of Technology Owerri

OkoyeUjunnwa Callista, Department of Management Technology

Federal University of Technology Owerri
Unfortunately however, the industry is also notorious for its adverse effect on sustainable development. For example, Nwokoro\&Onukwube (2011), reiterating Woolley (2000), opined that the construction industry is one of the leading destroyer of the environment, acting as a major consumer of non- renewable resources, produces substantial waste, pollutes air and water, and contributes to land dereliction in no small way (Wallbaum and Buerkin, 2003).

Sustainable development as a concept encourages countries to attain development by concurrently achieving the goals of an improved environment, a better economy, and a more equitable and inclusive society as opposed to compromising one of these for another (Ilesanmi, 2010). One of the primary goal of sustainability is to reduce humanity's environmental or ecological footprint on the planet. Sustainable development has given rise to green buildings. The main categories of green building practices are: energy saving, land saving, storm water runoff-reducing, material conservation and pollution reduction (ECO Northwest, 2001). A green building uses an average of $30 \%$ less energy than conventional building (Economist, 2004). Material waste generated during construction is reduced or recycled. Energy efficiency is improved, perhaps by relying on the use of natural light and ventilation or solar power. Less water is used, or rainwater harvesting system is installed to ensure wiser use. Measures taken to make buildings and construction more sustainable rely increasingly on life cycle approaches. Unfortunately, there are lack of institutional structures promoting green buildings; awareness on the part of clients, tenants, professionals in the built environment and other stake holders; professional capacity to incorporate green building issues and opportunities and; financial resources to undertake green building construction and upgrades.

The construction industry is a major consumer of the resources and produces a lion's share of waste. According to Agenda 21 in Dahiru (2005), the industry is often referred to as the 40 per cent industry as it is responsible for the consumption of approximately 40 percent of natural resources and about 40 per cent of all waste produced. Similarly, Dimson (1998) in Gandu (2005) observed that human habitats (buildings) is a major contributor to environmental crises through resources depletion, energy consumption, air pollution and creation of waste. In line with this, Ajatar (2000) outlines up to ten different adverse effects of construction activities on the environment. These include, among others, land misuse, existing site dereliction, habit destruction, misuse of natural resources, and so on. In 
addition, the on-site construction practices results in a number of health and comfort disturbances, especially to people living where construction activities are taking place.

One problem which is of great concern is the observation made by Schmidt (2000) that building activities are responsible for approximately one-third of ecological disasters. According to Kolawole\&Anigbogu (2005), the friendliest way to handle the environment is not to build. However, without construction, life can be miserable and threatening because shelter is needed, amongst other things, for protection against the inclement weather and for healthy living. Kolawole\&Anigbogu '(2005) state that what is needed is a dynamic equilibrium. In other words, production process that is friendly to the ecosystem, yet competitive and possess no any form of threat (Zubairu 2012) Environmentally friendly buildings, popularly called Green Buildings (GB), sustainable or high-performance buildings, seem to satisfy the above mentioned requirements.

Green building (also known as green construction or sustainable building) refers to a structure and using process that is environmentally responsible and resource-efficient throughout a buildings life-cycle from sitting to design, construction, operation, maintenance, renovation, and demolition (U.S. Environmental Protection Agency 2009). This requires close cooperation of the design team, the architects, the engineers and the client at all project stages ( $\mathrm{Ji}$ and Plainiotis, 2006). The green building practice expands and complements the classical building concerns of economy, utility, durability, and comfort (U.S. Environmental Protection Agency, 2009).

Green building measures can lead not only to lower building operating expenses through reduced utility and waste disposal. Cost, but also to lower on-going building maintenance cost ranging from salaries to suppliers. The emphasis is on efficiency. Sustainability is a goal that allows for the continuing improvement of standard of living without reversible damage to resources we need to survive as species (Lehrer, 2001). The green approach to Architecture is not something new as it has existed for years. What is new is the realization that green approach to the built environment involves a holistic approach to the design of buildings; that all the resources that go into a building, are their materials fuels or the contribution of the users need to be considered if sustainable architecture is to be produced (Brenda and Vale, 2007).

Embracing green or sustainable concept in design is aimed at reducing energy, operation and maintenance cost, reduce building related illness, increase the productivity and comfort of building occupants, reduce waste and pollution and increase building and component durability and flexibility. It is important that the focus of green concept be embraced from the early stages of building, planning and construction. Furthermore, green buildings holistically addresses the spotty performance of conventional buildings with respect to human health. There is ample evidence that $40 \%$ of all illnesses can be traced to buildings and homes where people live, work, or attend school, church or sporting events (Achyuthan and Balagopal, 2006). Conventional construction, unless forced to by lawsuits, generally ignores issues of Sick Building
Syndrome (SBS) or Building Related Illness (BRI). Green buildings meet the challenges of building health directly and provide several layers of consistent approaches that promote occupant health.

According to Gottfried (1996), the decision made at the first phase of building design and construction can significantly affect the costs and efficiencies of other phase as recent studies have shown that green building measures taken during construction or renovation can result in significant building operational savings, as well as increases in employee productivity. In essence, building related costs are best revealed and understood when they are analysed over the life span of the building. In Nigeria, green concept, sustainability and environmental issues are hardly put into consideration when designing a new building or renovating an old one. According to Otegbulu (2011), these results in a short fall in user satisfaction, functional space planning, service type and in addition sustainable building components are often neglected during design and construction.

High performance green buildings are facilities designed, built, operated, renovated, and disposed of using ecological principles for the purpose of promoting occupant's health and resource efficiency plus minimizing the impacts of the built environment on the natural environment. High performance green buildings have succeeded in their rapid and exponential penetration of construction market for three basic reasons. First, they are the ethical response to both global and local environmental and resource issues. A typical, code compliant building makes minimal efforts to address energy and water issues and totally ignores materials waste, impacts on the construction site and any other issue not specifically covered in the building codes. Green buildings take a far different approach.

\section{LITERATURE REVIEW}

\section{Theoretical framework}

Green Building (GB) is a holistic approach to programming, planning, designing, and constructing (or renovating) buildings. It is part of the larger concept of sustainable development as it enhances the environment against the negative side effect of construction activities. Besides, that all liabilities of materials, water and energy waste, and pollution emissions are converted into economic opportunities through the realization of environmentally sound, healthier and cost effective project. It has been described as a clear answer to health, economic and environmental challenges (Karolides 2002). Construction of Green Building entails tailoring a building and the site to the local climate, site conditions, cultural and community in order to reduce resource consumption, augment resource supply, and enhance the quality and diversity of life. This is achieved through analysing important and interrelated issues, such as, the site and climate, building orientation and form, lighting and thermal control system, and materials, while optimizing all these in an integrated design.

In other words, it is a total quality management approach to building in which right from the beginning of the project all the key people that would be involved at various stages of the execution of such project, are brought in. This is to ensure the 
achievement of synergistic design through interdisciplinary teamwork. Thus, Green Building as rightly observed by Karolides (2002), it is neither, an assemblage of environmental' components nor a piecemeal modification of an already designed standard building. It is neither a building style in which the building (Green Building) is expected to assume certain form or to have a "characteristic look". Rather, it is a building philosophy in which natural and resource efficient features are incorporated in a building.

Arguably, that Green Building makes an attempt to maximize operational energy savings, provide optimally healthy interior and limit the negative impact of construction activities, the professionals that usually participate in the construction of Green Building, increases considerably. For example, according to Walker (2002) Green Building design can take $40-100 \%$ more effort on the part of mechanical engineer or energy analyst. Apart from the mechanical engineer's role in the design and execution of conventional project, in Green Building, the calculation of energy use and analysis of the life-cycle energy use is their responsibility. However, this additional role is not restricted to the mechanical engineer all these professionals will carry out various analyses and calculations for optimal design solution, with respect to a specific building. Regarding the construction site selection, since emphasis is made on resource conservation and cultural preservation, renovating an existing building is preferred to new building.

If a new building is required, then Green Building 'should always be on those parts of land that are in the worst condition, not the best condition' (Karolides, 2002). Therefore, Infill and Brownfield sites should be considered first. An In-fill site is a vacant site within established urban area, not outskirt, while Brownfield site is an abandoned industrial site that would usually require rehabilitation work. Also site with adequate water sources and access to renewable energy like biomass, solar, and geothermal should be given priority for Green Building development.

On the other hand, ecologically sensitive land, suitable for agriculture, land of historical or cultural importance, or site that is prone to danger such as, flood, and wild fire should be avoided. Likewise, open spaces should not be used. In terms of the planning of settlement and the provision of infrastructural facilities, it is required to cut across all class of people in the society - the rich and poor, young and old. Relative to what is obtained in towns in Nigeria, where there is the Government Reserved Area (GRA). Materials to be used for the construction of (GB) are those that would ensure the achievement of sustainable built environment. This also applies to the actual construction of building that explains the reason why a Builder who is regarded as the "brain - box" of the project is expected to, among other things, carry out buildability and maintainability analysis, prepare production management document (PMD), develop elaborate plan for waste management even before the actual execution of the project.

According to a World Watch paper entitled 'A Building Revolution', the building industry is responsible for; $40 \%$ of world's total energy, $30 \%$ of consumption of raw materials, $25 \%$ of timber harvest, $35 \%$ of world's Carbon iv oxide
(CO2) emissions, $16 \%$ of fresh water withdrawal, $40 \%$ of municipal solid wastes, $50 \%$ of ozone- depleting Chlorofluorocarbons (CFC s) still in use, $55 \%$ of timber cut for non-fuel uses, $30 \%$ of the residents having sick building syndrome (Achyuthan and Balagopal, 2006). In contrast to conventional buildings, green buildings seek to use land and energy efficiently, conserve water and other resources, improve indoor and outdoor air quality, and increase the use of recycled and renewable materials. The Office of the Federal Environmental Executive offers a useful working definition. This agency defines this term as: "The practice of (1) increasing the efficiency with which buildings and their sites use energy, water, and materials, and (2) reducing building impacts on human health and the environment, through better citing, design, construction, operation, maintenance, and removal-the complete building life cycle."

\section{Water Efficiency}

Green homes also help conserve one of our most vital resources - water. Features like water harvesting, water recycling, water efficient fixtures, waste water reduction and water supply sub meters.New and more efficient products are one of the choices to reduce water consumption apart from changing or maintaining behaviour. A paper by Ezilondo further points out that simple solution such as feedback gargets and timers that help keep track of water used can reduce consumption (Ezilondo, Maria, Lofthouse, \& Victoria, 2010). Innovation in indigenous and green building approaches include rain water harvesting with segregation of surface and roof top run off. There is also the use of pervious paving to maximize ground water recharge. (UNEP SBCI, 2010). For instance in Melbourne, City Council House 11, a $72 \%$ reduction in mains water usage was achieved through a combination of water efficiency, rainwater harvesting, water recycling and sewer mining (Weizsacker, Smith, \& Desha, 2009).

Tessema (2010) also concurs that one of the water conservation ways in our context is harvesting, where the first catchment takes place on the roof top through a gutter system which flows into storage tanks that can be later used for irrigation and cleaning. Waste water can also be harvested at the house hold level (Tessema, Taipale, \& Jan Bethge, 2010). The use of water efficient fixtures and devices is more popular in the hotels than the office block; areas that can offer considerable savings by using efficient fixtures include bathrooms, laundry and kitchen. Other than efficient fixtures metering individual tenants can considerably reduce consumption by users (Mudgal, Lauranson, \& Bain, 2009). One of the most important elements of understanding water efficiency is the diversification of water terms in green building practices. In particular, the LEED standard identifies four key types: Potable Water, Gray water, Black water and Process Water; all of which provide different utilities in green building water efficiency processes.

\section{Energy Efficiency}

According to Santoli and Matteo (2003), the energy performance of a building must be calculated using standards that indicate the insulation of the buildings, the characteristics of technical systems and installed equipment. The position 
and orientation of the building in relation to other climatic aspects, exposure, its own capacity for renewable energy sources and other factors, such as indoor environmental quality, that could influence the energy requirements of the building.

The most important element of green building is energy efficiency. Higher levels of energy efficiency reduce carbon emissions - both from power plants and the home's own energy systems. Energy is a substantial and widely recognized cost of building operations, that can be reduced through energy efficiency and related measures. According to Gregory (2006), Green Building use 30\% less energy when compared to conventional buildings. A detailed review of 60 LEED (Leadership in Energy and Environmental Design) rated buildings (Gregory, 2006), demonstrates that Green Building, when compared to conventional buildings are:

i. On average $25-30 \%$ more energy efficient.

ii. Characterized by even lower electricity peak consumption.

iii. More likely to purchase grid power generated from renewable energy

Use of renewable energy sources, Use of Day lighting, Use of Artificial lighting control, Retrofitting old electrical fittings, Energy conservation measures.

\section{Sustainable Site Practice}

Site suitability enquiry is essential as this ensures that the site can legally and physically accommodate the type and size of project being envisaged. When selecting sites for developmental purposes avoid sites in noisy areas and ensure compatibility with existing facilities. Determine what else is planned for the site in the future (Nwafor, 2006). The features include adherence to local zoning requirements, preservation of existing vegetation, site landscaping and management of storm water.

\section{Indoor Environmental Quality}

The quality of indoor air depends on the concentration of pollutants at a particular moment in time. The perceived air quality is also dependent on the air temperature and the relative humidity which, in turn are linked. Health problems from inferior air quality include lung cancer, sick building syndrome(SBS), symptoms' and discomfort problems like bad smells and experience of dry air (Bornehag, et al.,2004).

The use of non-toxic materials, combined with natural ventilation and effective air filtration, can help improve indoor air quality, control indoor moisture levels, and protect occupants from mold, chemicals, combustion by-products and other indoor pollutants. The features include Ventilation to public and circulation spaces complaints arising from users, prevention of noise within and outside the building, low emitting paint and adhesive and low emitting flooring system.

The EPA's new Indoor air PLUS program has been designed to address the indoor environmental aspects of green building. Qualifying homes must first meet the efficiency guidelines for ENERGY STAR, and then incorporate additional design and construction features to control moisture, chemical exposure, radon, pests, ventilation, and filtration.

Creating thermal comfort for man is a primary purpose of the heating and air conditioning industry and this has a radical influence on the whole building industry. Comfort is not a product which is provided for building occupants, it is a goal which they achieve provided they are able to exert the necessary control over their environment (Shove et al., 2008). The control they exert over the environment will partly be decided by the building they occupy and its services and, may be subject to constraints (Cole et al., 2008). The aim of the building must be to allow occupants to achieve their comfort goal. People adapt more readily to thermal environments with which they are familiar. The building should therefore be designed to provide a thermal environment that is within the range customary for the particular type of accommodation, according to climate, season and cultural context.

\section{Waste Reduction and Disposal}

Considering efficiency in materials, green buildings address growing scarcity issues that many societies face due to unsustainable use of ecosystem services. To reduce building impact and to fulfil a complete life cycle of building and material construction impact, it is necessary to establish low impact criteria during design, construction, maintenance and disposal (Rode, 2011). The features include provision of waste management plan, provision of maintenance services, hazardous waste control and disposal and provision of different disposal methods.

The criteria to be followed include resource availability, minimal environmental impact, embodied energy efficiency, potential reuse and recyclability. Reducing the number of material components in products as well as separating natural from synthetic material allows higher rates of recyclability and reuse (Donough\&Mbraungart, 2002). According to Lawson the above criteria show that, for example, sustainably sourced wood is one of the best options for ensuring low embodied energy and minimal environmental impact. Lawson's study reported that 95 per cent of embodied energy that would otherwise go to waste can be saved by the reuse of building materials (Lawson, 1996).

Studies on recycling indicate that environmental impacts caused by reused materials are at 55 per cent of the impact caused if all materials had been new. (Thormark, 2006) Although recycling materials requires energy consumption, studies show that recycling materials still delivers net emissions savings (Sa'ra, 2001). In developing societies recycled building components are often cheaper and of higher quality than conventional materials (UNEP SBCI, 2010).

\section{RESEARCH METHODOLOGY}

This study was conducted through a survey research design and made use of both qualitative and quantitative modes of inquiries to assess the conformity of FUTO buildings to green building principles. According to Mugenda and Mugenda (1999), a combination of qualitative and quantitative methods is advantageous because they supplement each. Quantitative methods provide hard data whereas qualitative methods provide in depth explanations therefore the findings derived from one method validates the other.

The focus was on the buildings within FUTO with more concentration of new buildings constructed between 2012 and 2017 as relates to the scope of this study. FUTO have 
experienced a steady rise in the number of institutional buildings in the last five years. The primary data was obtained through observations and by administering questionnaires to individuals who are lecturers, familiar with the design, construction and management of the buildings. For quantitative method, parameters that define green construction with a range of variables from minimal to complete incorporation of the elements determined the degree of conformity. The degree of adoption was statistically analysed on the sampled buildings.

Two complexes were identified for this study in SEET complex and SMAT complex in FUTO as indicated in appendix 2. The choice of these two areas was informed by the fact that over $80 \%$ of major lecture hall buildings have been constructed in these two locations between the periods of the study. To maintain uniformity, premises that were sampled were limited to at least two floors and above. This ensured that the composition of the accessible population had the same characteristics hence homogeneous. SEET Complex construction commenced September 2011 and was completed July 2012. While SMAT Complex commenced October 2013 and completed February 2016. (By the then Vice Chancellor, Prof. Chigozie Cyril Asiabaka 2011-2016)

Due to time and resource constraints, the study was restricted to a portion of the target population of FUTO, Mugenda\&Mugenda, (Research Methods, Quantitative \& Qualitative approaches, 1999).

Finite Population: for a known population size of 162 .

$$
n=\frac{N}{\left(1+N e^{2}\right)}
$$

Where ' $\mathbf{n}$ ' is the sample size

' $\mathbf{N}$ ' is population size $=162$

Note; using a confidence level of $95 \%$

' $\mathrm{e}$ ' is alpha level $=0.05$

Table 1: Distribution of Questionnaires

\begin{tabular}{lll}
\hline Questionnaire & Frequency & Percentage $(\%)$ \\
\hline Number properly completed and returned & 91 & 79.0 \\
Numbers not returned & 24 & 21.0 \\
Total Number distributed & 115 & 100
\end{tabular}

\section{Source: Survey, 2017}

\section{Response to Questionnaires}

Questionnaires were sent out to lecturers in the building profession who have the knowledge in the design and
Mathematically; $n=\frac{N}{\left(1+N e^{2}\right)}=n=\frac{162}{\left(1+162\left(0.05^{2}\right)\right)}=$ 115 sample size.

Questionnaires designed in the form of a likert scale with closed and open ended questions were directed to different respondents which included Architects, Engineers, Project Managers, Builders, Planners, Environmentalist and Surveyors behind the sampled buildings. A 5-point Likertscale Questionnaire format (Very Great $=5$, Great $=4$, Moderate $=3$, Little $=2$, Not at all $=1$ ) was used to obtained the various perceptions of the professionals working in the Nigeria's Built Environment in FUTO.An inspection checklist that defines green construction with a range of variables from minimal to complete incorporation of the elements was prepared to determine the degree of conformity. Frequency and percentage count tables, Mean item score and Relative Importance Index (RII) and Ranks were used for data analyses.

\section{FINDINGS AND DisCUSSIONS}

In this study a sample size of 115 respondents from two sampled complexes was expected $(n=115)$ from Builders, Architects, Quantity surveyors, Town Planner, Land Surveyor, Environmentalist and Engineers, respectively.Data was obtained from self-administered questionnaires, completed by 91 participants $(n=91)$, this constituted a $79 \%$ response rate. Percentages reported correspond to the total number of lecturers in the building profession who answered the individual questions. Although neither the reasons for non-participation nor the characteristics of the non-respondents are known. implementation of 2 sampled complexes. The corresponding responses received are tabulated and represented graphically in figure 4.1

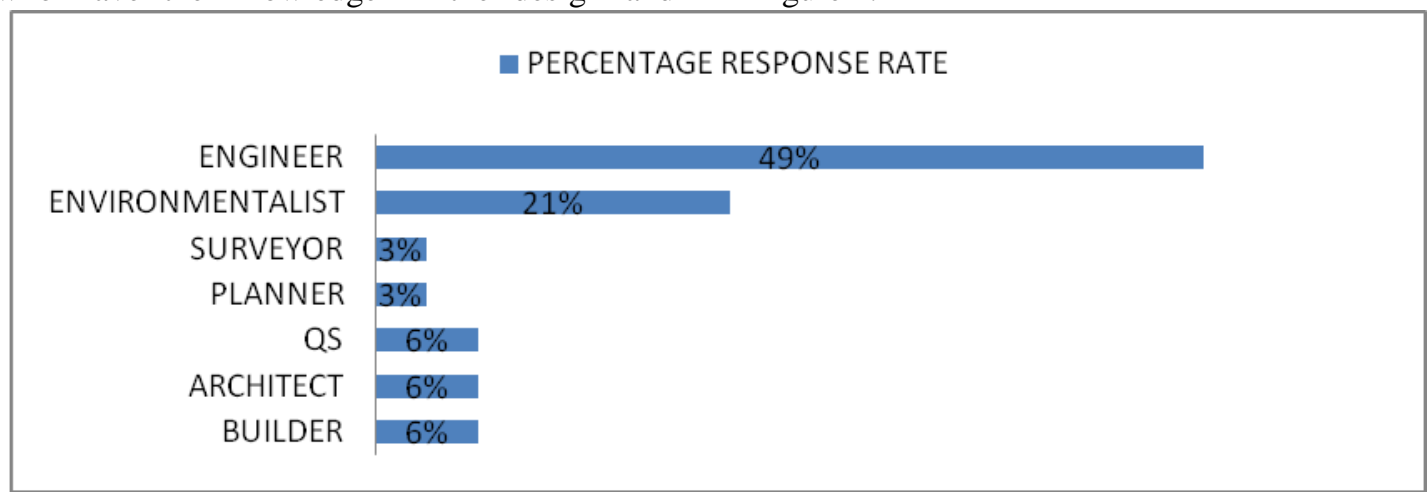

Figure 1: Response to questionnaires

Source: Survey, 2017

The Engineers comprising of the civil, electrical and

mechanical gave the highest response of $49 \%$ followed by the Environmentalists by $21 \%$. The Quantity Surveyors, 
Architects and Builders were all on 6\% each while the Land Surveyor and Urban planner were $3 \%$ each. However, the low Professional Experience

Table 2: Respondents Professional Experience

\begin{tabular}{lll}
\hline Experience & Frequency & Percentage $\mathbf{( \% )}$ \\
\hline Below 5 years & 5 & 7 \\
$6-10$ years & 32 & 36 \\
$11-15$ years & 5 & 7 \\
$16-20$ years & 27 & 29 \\
Over 20 years & 22 & 21 \\
Total & 91 & 100 \\
\hline
\end{tabular}

response rate was as a result of few respondents from those departments.

Source: Survey, 2017

As it can be observed from table 4.2, the highest percentage of experience is $36 \%$ and $29 \%$, which is between 6-10 years and 16-20 years of working experience respectively. The least experience level from the respondents is below 5 years and 11-15 years having 7\% each.

\section{Adoption of Green Building Concepts}

To assess the extent of adoption, the green building concepts were grouped into five environmental categories

Table3: Respondents' awareness on incorporation of GBCs

\begin{tabular}{lll}
\hline Response & Frequency & Percentage \\
\hline Yes & 33 & $36 \%$ \\
No & 52 & $57 \%$ \\
Not sure & 6 & $7 \%$ \\
\hline
\end{tabular}

Source: Survey, 2017

Table 3 revealed that the respondents in the sampled buildings were all aware of the green building concepts under the five environmental categories. However, 36\% confirmed this concept has been adopted in FUTO while 57\% disagreed. The rest of the $7 \%$ were not sure if it has been incorporated yet in FUTO. At this, the respondents who disagreed still went ahead to fill the questionnaire.

Environmental categories of Green Building Concept applied in FUTO

To further assess the extent of adoption of the green concepts, it was important to find out which among the five environmental categories had been applied in the projects during the last 5 years. The study found that some of the

namely water efficiency and conservation, energy efficiency, choice of site, indoor environmental quality, and waste disposal. The lecturers were initially asked if they were aware of the green building concepts and whether they had seen it incorporated in any projects in the last 5 years $(2012-2017)$ in FUTO. Below are their responses on both awareness and incorporation of the concepts.

Incorporation of Green Building Concepts in Projects

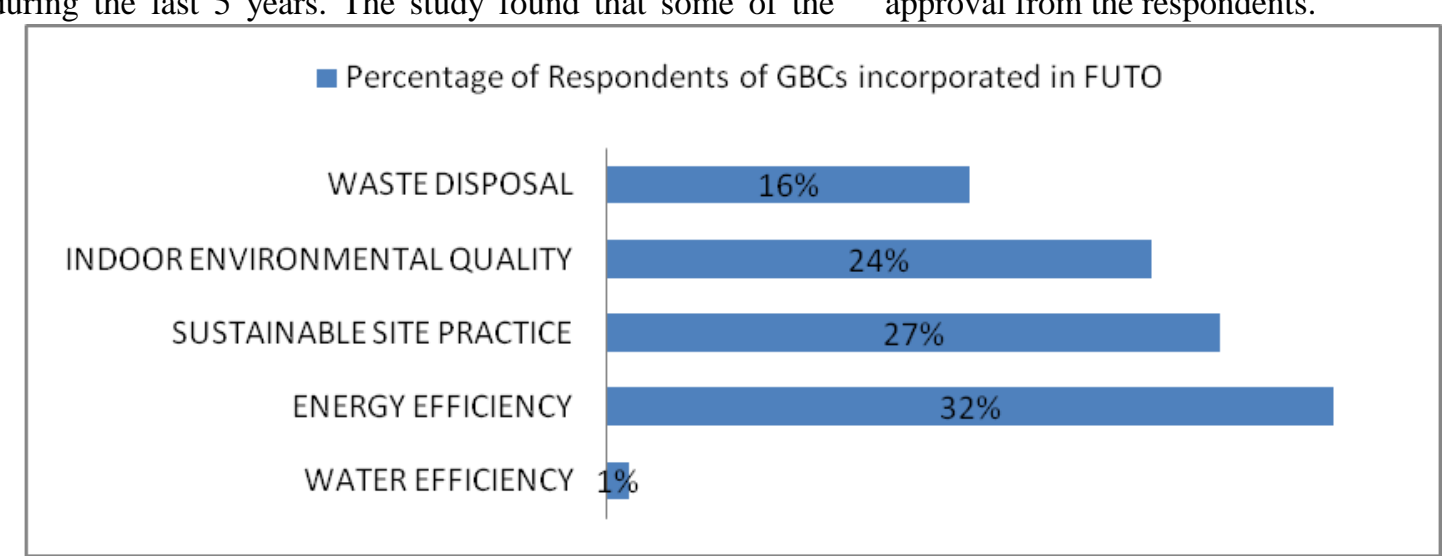

Figure 2: Percentage of respondents of GBCs incorporated in FUTO

Source: Survey, 2017

\section{Level of GBCAdoption}

To determine the extent of adoption of green building concepts, respondents were asked to use a 5 point likert scale to determine the extent the identified challenges in the consultants and practitioners had engaged in some level of green activities in all the environmental categories in FUTO. The level of incorporation of the five environmental categories is discussed below.

Level of Incorporation of the environmental categories

The study established that certain concepts in all the five environmental categories had been applied in the building projects. Concepts in the category of energy efficiency and use of sustainable site practice had been applied most with a score of $32 \%$ and $27 \%$ respectively. Energy efficiency attracted high score perhaps because of its daily usage in buildings. The least was water efficiency with barely $1 \%$ from approval from the respondents. literature review hinder increased adoption. A mean score was calculated and relative importance index (RII) where a higher RII meant that the concept is more incorporated whereas a lower RII was interpreted as a less incorporated. This was gotten from the questions collected and reaffirmed 
by the observation checklist by the researcher.

\section{Water efficiency and conservation concepts}

The study sought to find out the extent to which water efficiency and conservation concepts had been incorporated in FUTO buildings. It was revealed that rain water harvesting was barely ranked the highest with a relative importance index of 0.31 . This is closely followed by water efficient fixtures of 0.30 . This is due to the roofs having water channel sprouts, directing the rain water through pipes and channels to the ground. Drums are used to store rain water. In came third on the ranking was waste water reduction with a RII of 0.29 . Water supply sub meters is $4^{\text {th }}$ with RII of 0.24 ; it was also observed that none of the building complexes had installed water sub meters. Water recycling was the least of them all with RII of 0.21 ; recycling of water in form of irrigation counts less.

Furthermore, from the mean score of table 4, it can be deduced that water efficiency had been incorporated 'Not at all' tending to 'Little extent' in the sampled buildings. Davidson (Water conservation Group, 2010) observes that waste water in most cases is used for landscaping, irrigation, cleaning among other uses, however, studies suggest that most efficiency measures are in attitude rather than in the incorporation of the concepts (Ezilondo, Maria, Lofthouse, \& Victoria, 2010).

Table 4: Frequency and Ranking of Water Efficiency

\begin{tabular}{|c|c|c|c|c|c|c|c|c|c|c|}
\hline \multirow[t]{2}{*}{ Water efficiency } & \multicolumn{5}{|c|}{ Frequency } & \multirow[t]{2}{*}{$\Sigma$} & \multirow[t]{2}{*}{$\sum \mathbf{f x}$} & \multirow{2}{*}{ nea } & \multirow[t]{2}{*}{ RII } & \multirow{2}{*}{${ }_{k}$ Ran } \\
\hline & 1 & 2 & 3 & 4 & 5 & & & & & \\
\hline Rain water harvesting & 52 & 26 & 13 & - & - & 91 & 143 & 1.57 & 0.31 & $1^{\mathrm{st}}$ \\
\hline Water recycling & 85 & 6 & - & - & - & 91 & 97 & 1.07 & 0.21 & $5^{\text {th }}$ \\
\hline Water efficient fixtures & 52 & 33 & 6 & - & - & 91 & 136 & 1.49 & 0.30 & $2^{\text {nd }}$ \\
\hline Water waste reduction & 58 & 27 & 6 & - & - & 91 & 130 & 1.43 & 0.29 & $3^{\text {rd }}$ \\
\hline Water supply sub meters & 79 & 6 & 6 & - & - & 91 & 109 & 1.20 & 0.24 & $4^{\text {th }}$ \\
\hline
\end{tabular}

$1=$ Not at all, 2=Little extent, 3=Moderate extent, 4=Great extent, 5=Very great extent

Source: Survey, 2017

\section{Energy Efficiency}

The study sought to establish the extent to which energy efficiency concepts had been incorporated in FUTO buildings using table 4.5 , it was revealed that the use of day lighting was ranked highest under the relative importance index of 0.55 ; this is due to the large window sizes to enable direct sunlight penetrating and good ventilation. Use of bulbs and switches for artificial light control was ranked second with an RII of 0.43. Next was retrofitting old electrical fittings like

Table 5: Frequency and Ranking of Energy efficiency

\begin{tabular}{|c|c|c|c|c|c|c|c|c|c|c|}
\hline \multirow[t]{2}{*}{ Energy efficiency } & \multicolumn{5}{|c|}{ Frequency } & \multirow[t]{2}{*}{$\Sigma$} & \multirow[t]{2}{*}{$\sum \mathbf{f x}$} & \multirow{2}{*}{ n $^{\text {Mea }}$} & \multirow[t]{2}{*}{ RII } & \multirow{2}{*}{$k^{\operatorname{Ran}}$} \\
\hline & 1 & 2 & 3 & 4 & 5 & & & & & \\
\hline Use of renewable energy sources & 63 & 21 & 7 & - & - & 91 & 126 & 1.38 & 0.28 & $5^{\text {th }}$ \\
\hline Use of day lighting & 13 & 13 & 43 & 21 & - & 91 & 252 & 2.77 & 0.55 & $1^{\text {st }}$ \\
\hline Use of artificial control & 42 & 14 & 21 & 7 & 7 & 91 & 196 & 2.15 & 0.43 & $2^{\text {nd }}$ \\
\hline Retrofitting old electric fittings & 49 & 28 & 14 & - & - & 91 & 147 & 1.62 & 0.32 & $3^{\text {rd }}$ \\
\hline Energy conservation measures & 56 & 28 & 7 & - & - & 91 & 133 & 1.46 & 0.29 & $4^{\text {th }}$ \\
\hline
\end{tabular}

1=Not at all, 2=Little extent, 3=Moderate extent, 4=Great extent, 5=Very great extent

Source: Survey, 2017

\section{Sustainable Site Practice}

These findings indicate that adherence to the local zoning requirements, site landscaping, and preservation of existing vegetation and management of storm water are concepts which are not considered at either during design and construction or during building occupation and concurs with findings by Tessema, et al (2010) and Adebayo (2000). Adebayo (2000) argues that many urban areas of Africa especially in cities the construction of buildings occupy the entire site with total disregard to natural environment. Table 4.6 shows the extent to which the concept of sustainable site had been incorporated in FUTO. changing of switches and lamp holders that have worn out, had an RII of 0.32. Energy conservation measures such as switching off electrical appliances, was ranked $4^{\text {th }}$ on the RII. The least rank was the use of renewable energy sources. The little extent (RII of 0.28) of adoption of use alternative energy sources could possibly be attributed to lack of other stable sources of electricity supply.However, from the mean score of table 5, energy efficiency incorporation in FUTO is in 'Little extent'.
The study sought to establish the extent to which the concept of sustainable site had been incorporated in FUTO. At this, from table 4.6, the mean score indicate to a 'Little extent'. Adherence to local zoning requirements ranked the highest according to the respondents count. With a refractive importance index of 0.51 ; local zoning came out moderate. $2^{\text {nd }}$ rank was site landscaping with the school management improving on this has made it raked a RII of 0.49 . Preservation of existing vegetation was ranked $3^{\text {rd }}$ as being incorporated in FUTO. The least of them all was management of storm water with a RII of 0.35 . 
A View of the Adoption of Green Building Concept in Construction Projects in Federal University of Technology Owerri

Table 6: Frequency and Ranking of Sustainable site practice

\begin{tabular}{|c|c|c|c|c|c|c|c|c|c|c|}
\hline \multirow[t]{2}{*}{ Sustainable site practice } & \multicolumn{5}{|c|}{ Frequency } & \multirow{2}{*}{$\Sigma$} & \multirow[t]{2}{*}{$\sum \mathbf{f x}$} & \multirow{2}{*}{ Mea } & \multirow[t]{2}{*}{ RII } & \multirow{2}{*}{$k^{\text {Ran }}$} \\
\hline & 1 & 2 & 3 & 4 & $\overline{5}$ & & & & & \\
\hline $\begin{array}{l}\text { Adherence to local zoning } \\
\text { requirements }\end{array}$ & 21 & 13 & 43 & 14 & - & 91 & 232 & 2.55 & 0.51 & $1^{\mathrm{st}}$ \\
\hline Preservation of existing vegetation & 21 & 28 & 35 & 7 & - & 91 & 206 & 2.26 & 0.45 & $3^{\text {rd }}$ \\
\hline Site landscaping & - & 48 & 43 & - & - & 91 & 225 & 2.47 & 0.49 & $2^{\text {nd }}$ \\
\hline Management of storm water & 43 & 27 & 21 & - & - & 91 & 160 & 1.76 & 0.35 & $4^{\text {th }}$ \\
\hline
\end{tabular}

1=Not at all, 2=Little extent, 3=Moderate extent, 4=Great extent, 5=Very great extent

Source: Survey, 2017

\section{Performance in use and environmental quality}

Five concepts under environmental quality which included ventilation to spaces, complaints arising from users, noise control, use of low emitting paints and use of low emitting finishes were considered in this study in table 7.In the five concepts under environmental quality the study revealed that ventilation to public and circulation spaces was ranked highest with relative importance index of 0.55 ; although some offices vary in size the sampled buildings. So also complaints arising from users were $2^{\text {nd }}$ on the list with RII of 0.48 ; this is due to noise from the surrounding, low emitting paint and low emitting flooring. A jam-packed office was also a result for these complaints. Table 7 clearly indicate from the mean score that this category has been adapted to a 'Little extent'.

Table 7: Frequency and Ranking of Performance in use environmental quality

\begin{tabular}{|c|c|c|c|c|c|c|c|c|c|c|}
\hline \multirow{2}{*}{$\begin{array}{c}\text { Performance in } \\
\text { environmental quality }\end{array}$} & \multicolumn{5}{|c|}{ Frequency } & \multirow{2}{*}{$\sum$} & \multirow[t]{2}{*}{$\sum \mathbf{f x}$} & \multirow{2}{*}{ Mea } & \multirow[t]{2}{*}{ RII } & \multirow{2}{*}{ Ran } \\
\hline & 1 & 2 & 3 & 4 & $\overline{5}$ & & & & & \\
\hline $\begin{array}{l}\text { Ventilation to public and circulation } \\
\text { spaces }\end{array}$ & 7 & 21 & 49 & 14 & - & 91 & 252 & 2.77 & 0.55 & $1^{\text {st }}$ \\
\hline Complaints arising from users & 42 & - & 21 & 28 & - & 91 & 217 & 2.38 & 0.48 & $2^{\text {nd }}$ \\
\hline $\begin{array}{l}\text { Prevention of noise within and } \\
\text { outside the building }\end{array}$ & 63 & 28 & - & - & - & 91 & 119 & 1.31 & 0.26 & $5^{\text {th }}$ \\
\hline Low emitting paint and adhesive & 28 & 42 & 21 & - & - & 91 & 175 & 1.92 & 0.38 & $3^{\text {rd }}$ \\
\hline Low emitting flooring system & 35 & 35 & 21 & - & - & 91 & 168 & 1.85 & 0.37 & $4^{\text {th }}$ \\
\hline
\end{tabular}

$1=$ Not at all, 2=Little extent, 3=Moderate extent, 4=Great extent, 5=Very great extent

Source: Survey 2017

Waste reduction and disposal

Waste reduction and disposal have four categories; provision of waste management, provision of maintenance services, disposal of hazardous waste, and provision of different waste disposal method.The study revealed that provision of different disposal methods was ranked the highest with a RII of 0.43 ; this include reduction in waste, recycling and waste incineration in particular. Provision of maintenance services was second ranked with RII of 0.40 . Others were provision of waste management plan and hazardous waste control and disposal with RII of 0.34 and 0.29 respectively, according to table 4.8 .Just like the above mentioned categories of green building concept in FUTO, the extent of adoption from the mean score of table 8 is to a 'Little extent'.

Table 8: Frequency and Ranking of Waste reduction and disposal

\begin{tabular}{|c|c|c|c|c|c|c|c|c|c|c|}
\hline \multirow[t]{2}{*}{ Waste reduction and disposal } & \multicolumn{5}{|c|}{ Frequency } & \multirow[t]{2}{*}{$\Sigma$} & \multirow[t]{2}{*}{$\sum \mathbf{f x}$} & \multirow{2}{*}{ Mea } & \multirow[t]{2}{*}{ RII } & \multirow{2}{*}{$k{ }^{\operatorname{Ran}}$} \\
\hline & 1 & 2 & 3 & 4 & 5 & & & & & \\
\hline Provision of waste management plan & 35 & 49 & 7 & - & - & 91 & 154 & 1.69 & 0.34 & $3^{\text {rd }}$ \\
\hline Provision of maintenance services & 21 & 49 & 21 & - & - & 91 & 182 & 2.00 & 0.40 & $2^{\text {nd }}$ \\
\hline Hazardous waste control and disposal & 70 & 7 & 7 & 7 & - & 91 & 133 & 1.46 & 0.29 & $4^{\text {th }}$ \\
\hline Provision of different disposal & 15 & 49 & 27 & - & - & 91 & 194 & 2.13 & 0.43 & $1^{\mathrm{st}}$ \\
\hline
\end{tabular}

methods

1=Not at all, 2=Little extent, 3=Moderate extent, 4=Great extent, 5=Very great extent

Source: Survey, 2017

\section{CONCLUSION AND RECOMMENDATIONS}

The first objective of the study was to identify the extent of adoption of Green Building concept in FUTO. To investigate the extent of adoption, the green building concepts were grouped into five environmental categories namely water efficiency and conservation, energy efficiency, choice of site, indoor environmental quality, and waste disposal were taken into consideration.

The study established that certain concepts in all the five environmental categories had been applied in the building projects. Concepts in the category of energy efficiency and 
use of sustainable site practice had been applied most with a score of $27 \%$ and $23 \%$ respectively. Energy efficiency attracted high score perhaps because of its daily usage in buildings. Indoor environmental quality has a score of $20 \%$ while $13 \%$ was for waste disposal. The least was water efficiency with barely $2 \%$ from approval from the respondents.

There has to be a comprehensive policy on green building principles and a concerted effort towards implementation. Here in FUTO, if green building principles are not integrated into government policies for building projects, its implementation will be difficult. The present and the future building concepts lie in the green building principles and as such, FUTO cannot afford not to conform to it. Green building concept is at the very essence of the principle of environmental sustainability.

Green Building is not practiced in FUTO; there is no any enabling environment in the form of legislation or policy on Green Building practice; the overall perception of Green Building from all the groups of respondents has revealed that most professionals are aware of the new trend (Green Building). The enormous benefits derived from it and they see Green Building as a basis for appealing livable homes and preserving natural resources while taking care of their health. However, the general public are not fully aware of this development i.e. level of awareness of Green Building is low.

\section{REFERENCES}

[1] Achyuthan A, Balagopal T S P (2006) - Green Architecture Traditional and Modern 'A paper presented at the 22nd National Convention of Architectural Engineers organized by The Institution of Engineers (India) at Trichur during November 1-2, 2006.

[2] Ajatar, U. (2000) - "Project Impacts and Mitigation - A challenge for Nigerian Construction Practioners in the 3 Millennium" Environmental Review, Vol. 3(2), 343 - 349.

[3] Berke, P.R., 2002 - Does sustainable development offer a new direction for planning? Challenges for the twenty-first century? Journal of Planning Literature 17, 21-36.

[4] Bornehag, C.G., Blomquist, G., Gyntelberg, F., Ja"rvholm, B.,Malmberg, P., Nordvall, L., Nielsen, A., Pershagen, G. and Sundell, J. (2001) - Dampness in Buildings and Health. Nordic Interdisciplinary Review of the Scientific.

[5] Brenda and Vale, R. (2007) - Principles of Green Architecture. The Sustainable Urban Development.

[6] Cole, R.J., Robinson, J., Brown, Z. and O'shea, M. (2008) Recontextualizing the notion of Comfort. Building Research \& Information, 36(4), 232-336 